\title{
Seleno-L-Methionine Suppresses Immunoglobulin E-Mediated Allergic Response in RBL-2H3 Cells
}

\author{
Tomohiro Arakawa, ${ }^{*}$ Haruki Okubo, Midori Mae, Tomofumi Okuno, Hirofumi Ogino, and \\ Hitoshi Ueno
}

Department of Public Health \& Preventive Pharmacology, Faculty of Pharmaceutical Sciences, Setsunan University; 45-1 Nagaotoge-cho, Hirakata, Osaka 573-0101, Japan.

Received February 5, 2019; accepted April 7, 2019; advance publication released online April 12, 2019

\begin{abstract}
The effect of seleno-L-methionine (SeMet) on immunoglobulin (Ig) E-mediated allergic responses were investigated using rat basophilic leukemia RBL-2H3 cells. Cells were first treated with or without SeMet, sensitized with anti-dinitrophenyl IgE and stimulated with the antigen dinitrophenyl-human serum albumin, before the measurement of degranulation, calcium mobilization, mRNA expression and protein secretion of interleukin (IL)-4 and tumor necrosis factor (TNF)- $\alpha$, and phosphorylation of spleen tyrosine kinase (Syk), Akt, and mitogen-activated protein kinases (MAPKs). The antigen-induced $\beta$-hexosaminidase release, a degranulation marker, was significantly inhibited by SeMet treatment. SeMet also significantly suppressed antigen-induced calcium mobilization. Antigen-induced increases in the mRNA expression and protein secretion of IL-4 and TNF- $\alpha$ were both significantly attenuated by SeMet treatment. In addition, SeMet significantly suppressed antigen-induced phosphorylation of Syk, Akt, and MAPKs. These results demonstrate that SeMet suppresses antigen-induced degranulation, and mRNA expression and protein secretion of IL-4 and TNF- $\alpha$, and inhibits antigen-induced mobilization of calcium and activation of Syk, Akt, and MAPKs. Our study provides valuable information that may be useful in the prevention and treatment of allergic diseases.
\end{abstract}

Key words seleno-L-methionine; degranulation; mast cell; interleukin 4; tumor necrosis factor $\alpha$

\section{INTRODUCTION}

Mast cells are closely related to allergic diseases such as asthma and atopic dermatitis and play essential roles in the allergic responses. ${ }^{1)}$ Mast cells express the type I Fc epsilon receptor (FceRI) that forms a complex with antigen-specific immunoglobulin (Ig) E. ${ }^{2)}$ When IgE-sensitized mast cells are stimulated with antigens, various allergic mediators, such as histamine, cytokines, and eicosanoids are secreted from mast cells and induce allergic reactions. ${ }^{3)}$ Activated mast cells also release $\beta$-hexosaminidase with the release of various allergic mediators. $\beta$-Hexosaminidase is stored in the secretory granules of mast cells, and it is commonly used as a marker of degranulation. ${ }^{4)}$ Mast cells produce various cytokines, such as interleukin (IL)-4 and tumor necrosis factor (TNF)- $\alpha$, which are critical in the inflammatory responses of late-phase reactions. $^{5)}$

When antigens trigger IgE-sensitized mast cells, spleen tyrosine kinase (Syk) is activated. ${ }^{6}$ Syk is considered an important molecule in the allergic response associated with FceRI signaling. The activation of Syk activates the phospholipase (PL) $\mathrm{C} \gamma$ and causes the mobilization of calcium, which is essential for degranulation. ${ }^{7)}$ The activation of Syk also causes the activation of downstream signaling molecules such as Akt and mitogen-activated protein kinases (MAPKs). ${ }^{4)}$ MAPKs consist of the extracellular signal-regulated kinase (ERK) $1 / 2$, p38, and c-Jun N-terminal kinase (JNK). The Akt and MAPK pathways play a crucial role in the expression of cytokines. ${ }^{4}$

Selenium is an essential trace element for the health of humans and animals, and we are ingested through the consumption of food. ${ }^{8)}$ Selenium is an element constituting the selenoproteins, through which its biological effects are pri- marily exerted. Glutathione peroxidase (GPx) and thioredoxin reductase are well-known selenoproteins, and they work to protect against oxidative stress. ${ }^{9)}$ Seleno-L-methionine (SeMet) is an organic selenium compound and is one of the major selenium chemical forms contained in food. ${ }^{8}$ SeMet shows greater bioavailability and milder toxicity than inorganic selenium compounds. ${ }^{8}$ Therefore, SeMet is considered to be one of the most useful chemical forms for nutritional supplementation. ${ }^{10}$

People suffering from allergic diseases have been reported to have significantly lower selenium concentrations and significantly lower GPx activity in blood than healthy individuals. ${ }^{11,12)}$ In addition, according to a cohort study on atopic dermatitis, low selenium levels increase the risk of atopic dermatitis. ${ }^{13)}$ It has been reported that an increase in oxidative stress is related to the pathogenesis of allergic diseases such as atopic dermatitis. ${ }^{14)}$ Moreover, it has also been reported that an increase in oxidative stress is related to the activation of mast cells. ${ }^{15)}$ From these considerations, we speculated that selenium could aid the prevention of allergic diseases. We have previously reported that supplementation with SeMet suppresses immediate allergic reactions stemming from ovalbumin-induced active cutaneous anaphylaxis (ACA) reactions in mice. ${ }^{16)}$ Moreover, we also revealed that supplementation with SeMet suppresses chronic allergic reactions resulting from atopic dermatitis induced by repeated application of 2,4,6-trinitrochrolobenzene (TNCB) in mice. ${ }^{17)}$ However, the effect of SeMet on IgE-mediated allergic response in mast cells has yet to be understood.

Rat basophilic leukemia (RBL)-2H3 cells have structural and functional characteristics of mast cells, ${ }^{18)}$ and have been commonly used in cell biological and biochemical researches of mast cell function. ${ }^{19)}$ In this study, to clarify the effect of 
SeMet on IgE-mediated allergic responses of mast cells, we investigated the effects of SeMet on antigen-induced degranulation and cytokine expression in IgE-sensitized RBL-2H3 cells. In addition, the effects of SeMet on the antigen-induced mobilization of calcium and activation of Syk, Akt, and MAPKs in IgE-sensitized cells were also investigated.

\section{MATERIALS AND METHODS}

Reagents Dinitrophenyl-human serum albumin (DNP-HSA), Anti-DNP-IgE, 4-nitrophenyl $N$-acetyl- $\beta$-Dglucosaminide, minimum essential medium (MEM) were provided by Sigma-Aldrich (St. Louis, MO, U.S.A.). SeMet was provided by Acros Organics (Geel, Belgium). Methionine (Met) was provided by Wako Pure Chemical Industries, Ltd. (Osaka, Japan).

Cell Culture RBL-2H3 cells were provided by the National Institutes of Biomedical Innovation, Health and Nutrition (Osaka, Japan). Cells were maintained in MEM containing $10 \%$ heat-inactivated fetal bovine serum, $100 \mathrm{mg} / \mathrm{mL}$ streptomycin, and $100 \mathrm{U} / \mathrm{mL}$ penicillin at $37^{\circ} \mathrm{C}$ in air containing $5 \% \mathrm{CO}_{2}$. Cells were seeded into plates, settled for $3 \mathrm{~h}$, treated with or without SeMet or Met, and incubated for $24 \mathrm{~h}$. After incubation, anti-DNP $\operatorname{IgE}(0.2 \mu \mathrm{g} / \mathrm{mL})$ was added and incubated for another $24 \mathrm{~h}$. Then, this SeMet and IgE-treated cells were used for each experiment.

Cell Viability Assay Cells were treated with the antigen DNP-HSA $(20 \mathrm{ng} / \mathrm{mL})$ for $2 \mathrm{~h}$, followed by 3-(4,5-dimethyl2-thiazolyl)-2,5-diphenyltetrazolium bromide (MTT) solution was added. After incubation for $4 \mathrm{~h}$, the medium was removed, dimethyl sulfoxide was added, and the absorbance at $550 \mathrm{~nm}$ was measured by $\mathrm{SH}-1000 \mathrm{Lab}$ microplate reader (Corona Electric Co., Ltd., Ibaraki, Japan).

Measurement of $\boldsymbol{\beta}$-Hexosaminidase Release $\beta$-Hexosaminidase release was performed as described by Murata et al. $^{20)}$ with slight modifications. Briefly, the medium of the cells was replaced with siraganian $(+)$ buffer $(119 \mathrm{mM}$ $\mathrm{NaCl}, 25 \mathrm{mM}$ PIPES, $5.6 \mathrm{mM}$ glucose, $1 \mathrm{mM} \mathrm{CaCl}_{2}, 5 \mathrm{mM}$ $\mathrm{KCl}, 0.4 \mathrm{mM} \mathrm{MgCl}, 0.1 \%$ bovine serum albumin (BSA), and $40 \mathrm{mM} \mathrm{NaOH}, \mathrm{pH} 7.2$ ) and incubated for $30 \mathrm{~min}$ at $37^{\circ} \mathrm{C}$ and $5 \% \mathrm{CO}_{2}$. Cells were stimulated with the antigen DNP-HSA $\left(20 \mathrm{ng} / \mathrm{mL}\right.$ ) for $30 \mathrm{~min}$ at $37^{\circ} \mathrm{C}$ and $5 \% \mathrm{CO}_{2}$, then the supernatant was collected, and the cells were lysed using siraganian (+) buffer supplemented with $0.1 \%$ Triton X-100. The cell lysates or the supernatants were transferred to a 96-well plate, and $0.1 \mathrm{M}$ citrate buffer ( $\mathrm{pH} 4.5$ ) containing $2 \mathrm{mM}$ 4-nitrophenyl $N$-acetyl- $\beta$-D-glucosaminide was added and incubated at $37^{\circ} \mathrm{C}$ for $1 \mathrm{~h}$. The reaction was stopped by adding $0.1 \mathrm{M}$ $\mathrm{Na}_{2} \mathrm{CO}_{3} / \mathrm{NaHCO}_{3}$ ( $\mathrm{pH} 10.0$ ), and the absorbance at $405 \mathrm{~nm}$ was measured by SH-1000Lab (Corona Electric Co., Ltd.). The results are expressed as a percentage of the total content of $\beta$-hexosaminidase in the cells.

Measurement of Calcium Mobilization Calcium mobilization was measured by the Calcium Kit-Fluo 4 (Dojindo Laboratories, Kumamoto, Japan), which was performed in accordance with the manufacturer's instructions. Briefly, cells were treated with Fluo 4-AM for $1 \mathrm{~h}$, then the antigen DNP-HSA $(20 \mathrm{ng} / \mathrm{mL})$ was added via an injector of TriStar microplate reader (Berthold Technologies, Bad Wildbad, Germany), and the fluorescence intensity was measured (Excitation: $485 \mathrm{~nm} /$ Emission: $535 \mathrm{~nm}$ ).
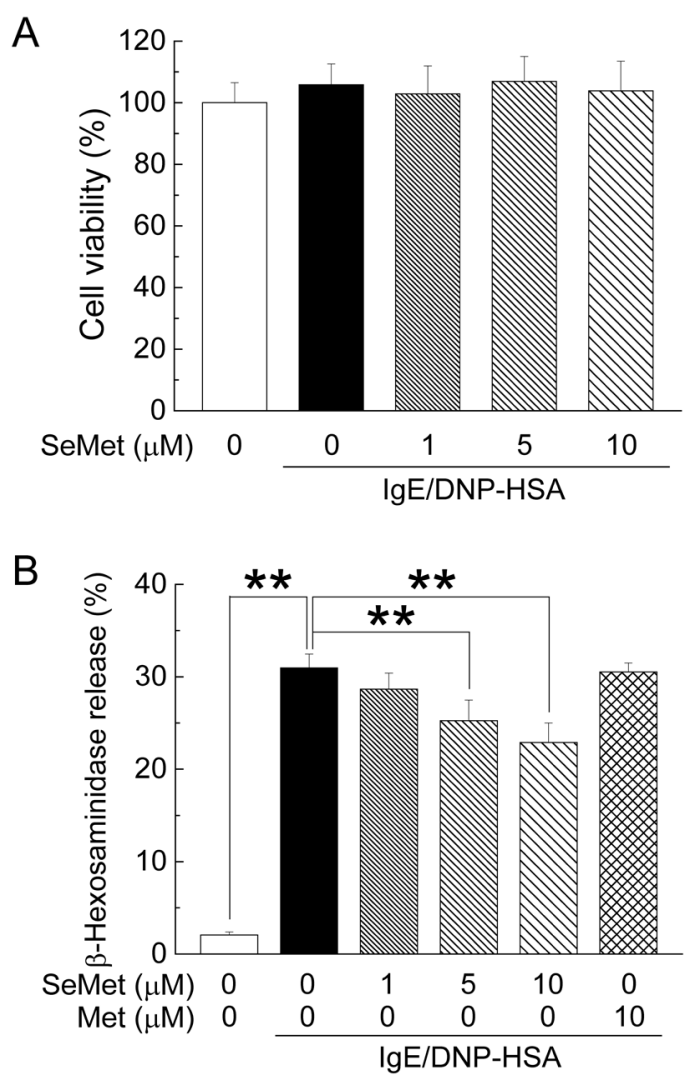

Fig. 1. Effect of SeMet on $\beta$-Hexosaminidase Release

(A) RBL-2H3 cells were treated with DNP-HSA for $2 \mathrm{~h}$, and cell viability was measured by MTT assay. (B) RBL-2H3 cells were treated with DNP-HSA for $30 \mathrm{~min}$, and $\beta$-hexosaminidase release was measured. The results are expressed as the mean \pm standard deviation (S.D.) $(n=6$ : cell viability; $n=8$ : $\beta$-hexosaminidase release). Experiments were repeated at least four times independently, and similar results were obtained. ${ }^{*} p<0.01$.

RNA Isolation and Real-Time Quantitative PCR Cells were treated with the antigen DNP-HSA $(20 \mathrm{ng} / \mathrm{mL})$ for $2 \mathrm{~h}$. RNA isolation and real-time quantitative PCR was performed as described in our previous study. ${ }^{17}$ ) The denaturation was carried out at $95^{\circ} \mathrm{C}$ for $10 \mathrm{~s}$. The annealing condition was as follows: ribosomal protein $\mathrm{S} 18$ (Rps18): $60^{\circ} \mathrm{C}$ for $10 \mathrm{~s}$; IL-4: $60^{\circ} \mathrm{C}$ for $20 \mathrm{~s}$; TNF- $\alpha$ : $55^{\circ} \mathrm{C}$ for $10 \mathrm{~s}$. The extension condition was as follows: Rps18 and TNF- $\alpha$ : $72^{\circ} \mathrm{C}$ for $10 \mathrm{~s}$; IL-4: $72^{\circ} \mathrm{C}$ for $30 \mathrm{~s}$. The cycle condition was 55 cycles. The results are expressed as the relative mRNA level compared with the expression of Rps18 mRNA. Primer sequences used were as follows: Rps18 forward: 5'-AAGTTT CAGCAC ATC CTGCGA GTA-3'; and Rps18 reverse: 5'-TTGGTGAGG TCA ATG TCT GCT TTC-3'; IL-4 forward: 5'-ACC TTGCTG TCA CCC TGT TC-3'; IL-4 reverse: 5'-GTGTTCCTT GTT GCGGTAAG-3'; TNF- $\alpha$ forward: 5'-TGA ACT TCGGGG TGA TCG-3'; TNF- $\alpha$ reverse: 5'-GGGCTT GTC ACT CGA GTT TT-3'.

Measurement of IL-4 and TNF- $\alpha$ Proteins Cells were treated with the antigen DNP-HSA $(20 \mathrm{ng} / \mathrm{mL})$ for $2 \mathrm{~h}$, and the cell culture supernatant was collected. The amount of IL-4 and TNF- $\alpha$ in the cell culture supernatant were determined by enzyme-linked immunosorbent assay (ELISA) (IL-4: Thermo Fisher Scientific, Waltham, MA, U.S.A.; TNF- $\alpha$ : BioLegend, San Diego, CA, U.S.A.) according to the manufacturer's instructions.

Western Blot Analysis Cells were treated with the antigen DNP-HSA $(20 \mathrm{ng} / \mathrm{mL})$ for $10 \mathrm{~min}$. Western blot analysis 
was performed as described in our previous study. ${ }^{21)} \mathrm{Mem}-$ branes were incubated with antibodies against phospho-Syk (Tyr525/526) (C87C1), Syk (D3Z1E), phospho-Akt (Ser473) (D9E), Akt (C67E7), phospho-ERK1/2 (D13.14.4E), ERK1/2 (137F5), phospho-p38 (D3F9), p38 (D13E1), phospho-JNK, JNK (Cell Signaling Technology, Danvers, MA, U.S.A.), and $\beta$-actin (AC-15) (Sigma-Aldrich). After incubation with sec-

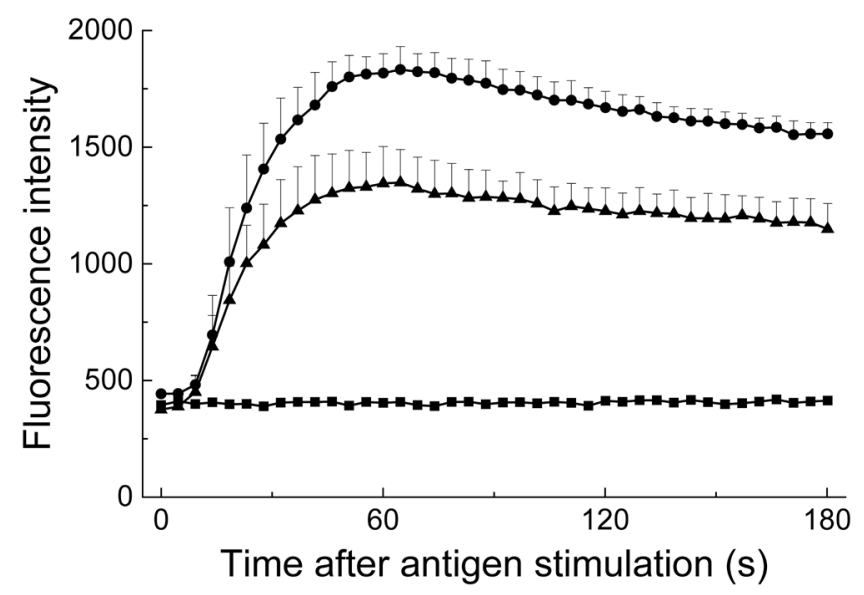

Fig. 2. Effect of SeMet on Calcium Mobilization

RBL-2H3 cells were treated with DNP-HSA, and fluorescence intensity for $3 \mathrm{~min}$ from the time of antigen stimulation was measured. Squares, negative control; circles, IgE/DNP-HSA; triangles, IgE/DNP-HSA + SeMet. The results are expressed as the mean \pm S.D. $(n=4)$. Experiments were repeated at least four times independently, and similar results were obtained.
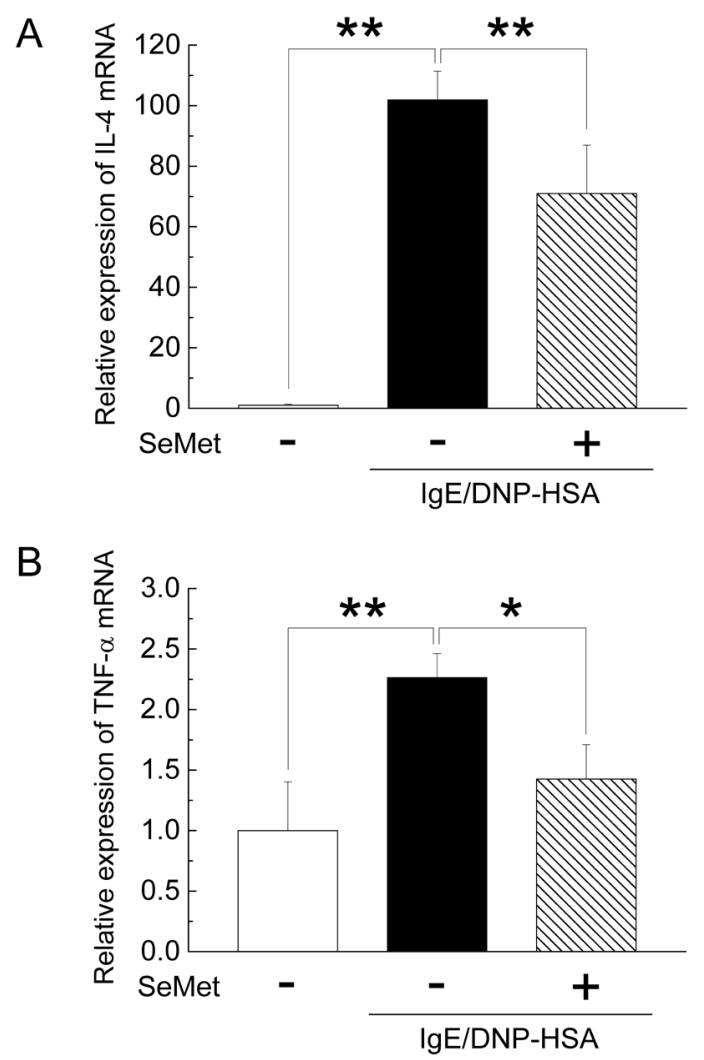

Fig. 3. Effect of SeMet on IL-4 and TNF- $\alpha$ mRNA Expression

RBL-2H3 cells were treated with DNP-HSA for $2 \mathrm{~h}$, and total RNA was isolated. The mRNA expression levels of IL-4 (A) and TNF- $\alpha$ (B) were measured by realtime quantitative PCR. The results are expressed as the mean \pm S.D. $(n=4)$. Experiments were repeated at least four times independently, and similar results were obtained. ${ }^{* *} p<0.01,{ }^{*} p<0.05$. ondary antibody, the protein expressions were detected using ECL reagent (GE Healthcare, Oxford, U.K.) and ChemiDoc MP (Bio-Rad Laboratories, Hercules, CA, U.S.A.). Quantitative Western blot data were obtained using Image Lab software (Bio-Rad Laboratories).

Statistical Analysis Statistical analysis was conducted by one-way ANOVA with the Bonferroni post hoc test. Origin Pro 9.0 J software (LightStone Corp., Tokyo, Japan) was used for statistical analysis.

\section{RESULTS}

Effect of SeMet on $\boldsymbol{\beta}$-Hexosaminidase Release and Calcium Mobilization We first measured the effect of SeMet treatment on the viability of RBL-2H3 cells. As shown in Fig. $1 \mathrm{~A}$, cell viability was not affected by SeMet treatment at increasing concentrations up to $10 \mu \mathrm{M}$.

To investigate the effect of SeMet on degranulation, $\beta$-hexosaminidase release, a general marker of degranulation, was measured. Cells were treated with or without SeMet, sensitized with IgE, and stimulated with antigen. As shown in Fig. 1B, $\beta$-hexosaminidase release was significantly increased upon antigen stimulation of IgE-sensitized cells compared with levels in negative control cells. Increase in $\beta$-hexosaminidase release by antigen stimulation was inhibited by SeMet treatment in a dose-dependent manner and was suppressed $28 \%$ at a concentration of $10 \mu \mathrm{M}$ of SeMet. Antigen-induced $\beta$-hexosaminidase release was not significantly inhibited by $10 \mu \mathrm{M}$ of Met. Since $\beta$-hexosaminidase release
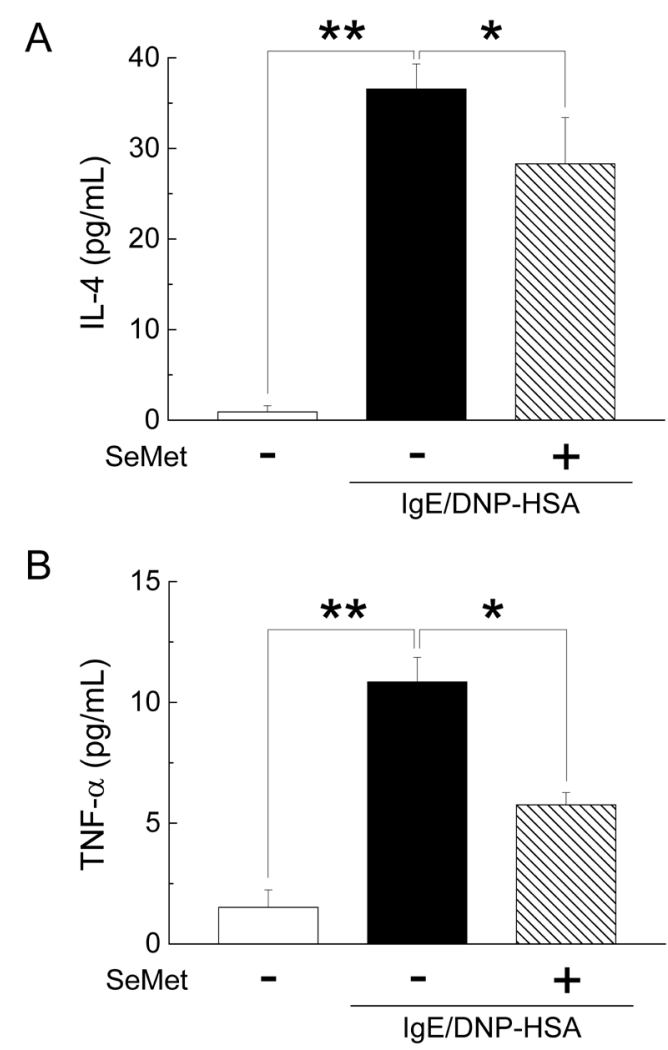

Fig. 4. Effect of SeMet on IL-4 and TNF- $\alpha$ Protein Secretion

RBL-2H3 cells were treated with DNP-HSA for $2 \mathrm{~h}$, and IL-4 (A) and TNF- $\alpha$ (B) secretion in the culture supernatant was measured by ELISA. The results are expressed as the mean \pm S.D. $(n=4)$. Experiments were repeated at least four times independently, and similar results were obtained. ${ }^{* *} p<0.01,{ }^{*} p<0.05$. 

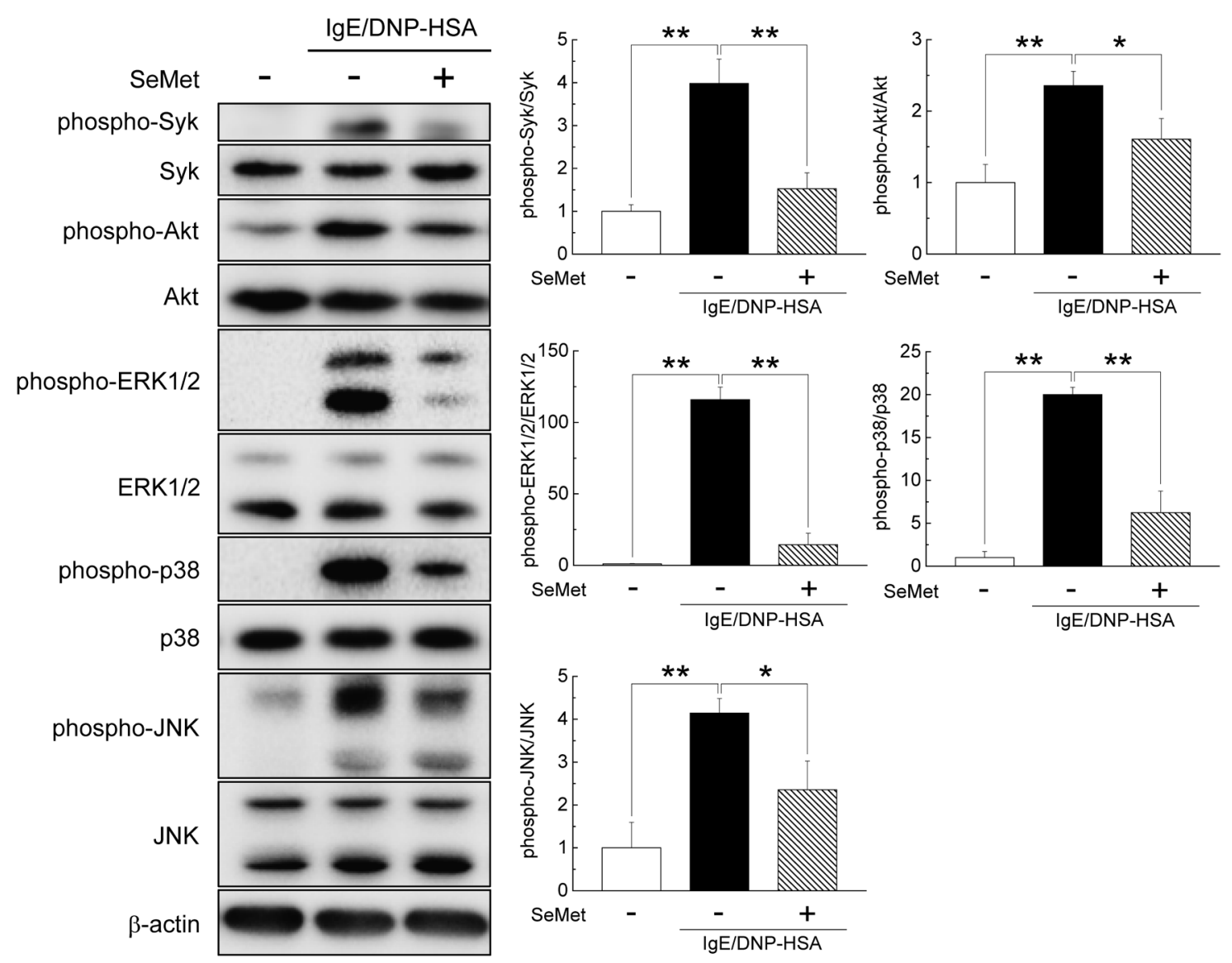

Fig. 5. Effect of SeMet on Phosphorylation of Syk, Akt, and MAPKs

RBL-2H3 cells were treated with DNP-HSA for $10 \mathrm{~min}$, and cell extracts were subjected to immunoblotting with antibodies against the target. Quantitative results are expressed as the mean \pm S.D. $(n=4)$. Experiments were repeated at least four times independently, and similar results were obtained. $* * p<0.01, * p<0.05$.

was most effectively suppressed at a concentration of $10 \mu \mathrm{M}$ of SeMet, SeMet was used at a concentration of $10 \mu \mathrm{M}$ in subsequent experiments.

We also measured calcium mobilization, which is involved in the regulation of degranulation. Cells were treated with or without SeMet and sensitized with IgE. The cells were then treated with Fluo 4, a fluorescent calcium probe, and stimulated with antigen. The fluorescence intensities for $3 \mathrm{~min}$ from the time of antigen stimulation were shown in Fig. 2. These results indicated that the fluorescence intensities, which are indicated the intracellular calcium levels, were increased by antigen stimulation in IgE-sensitized cells, and showed the highest value of about $1 \mathrm{~min}$ after antigen stimulation. Increase in fluorescence intensity by antigen stimulation was significantly suppressed by SeMet treatment, and was $34 \%$ lower with SeMet treatment at 1 min after antigen stimulation.

Effect of SeMet on the mRNA Expression and Protein Secretion of IL-4 and TNF- $\boldsymbol{\alpha}$ The effect of SeMet on the mRNA expression and protein secretion of IL- 4 and TNF- $\alpha$ was measured. Cells were treated with or without SeMet, sensitized with $\operatorname{IgE}$, and stimulated with antigen. After incubation, the cells were used for real-time quantitative PCR analysis, while the supernatant was used for ELISA. As shown in Figs. 3A and B, the expression of IL- 4 and TNF- $\alpha$ mRNA was upregulated upon antigen stimulation in $\mathrm{IgE}$-sensitized cells. Increase in IL- 4 and TNF- $\alpha$ mRNA expression level by antigen stimulation was 31 and $66 \%$ suppressed by SeMet treatment, respectively. In addition, as shown in Figs. 4A and B, IL- 4 and TNF- $\alpha$ protein secretion from antigen-stimulated IgE-sensitized cells was also increased. Increases in IL-4 and TNF- $\alpha$ protein secretion after antigen stimulation were 23 and $55 \%$ lower, respectively, due to SeMet treatment.

Effect of SeMet on the Phosphorylation of Syk, Akt, and MAPKs To elucidate the effect of SeMet on the activation of Syk, Akt, and three MAPKs, the phosphorylation levels of Syk, Akt, and three MAPKs were investigated. Cells were treated with or without SeMet, sensitized with IgE, and stimulated with antigen. As shown in Fig. 5, the phosphorylation level of Syk was significantly increased by antigen stimulation of IgE-sensitized cells and was significantly decreased by SeMet treatment. In addition, the phosphorylation levels of Akt, ERK1/2, p38, and JNK were also significantly increased by antigen stimulation in IgE-sensitized cells and were significantly decreased by SeMet treatment.

\section{DISCUSSION}

We previously reported that the administration of SeMet suppressed immediate allergic reactions and chronic allergic reactions in mice. ${ }^{16,17)}$ However, the effect of SeMet on the IgE-mediated allergic response in mast cells is yet to be elucidated. Our present data demonstrate that SeMet suppresses the antigen-induced allergic response in IgE-sensitized RBL-2H3 cells. 
We first investigated the effect of SeMet on cell proliferation by MTT assay. As the growth of RBL-2H3 cells was not affected by $10 \mu \mathrm{M}$ SeMet, we used $10 \mu \mathrm{M}$ SeMet in this study. It has been reported that human blood selenium levels are 1 to $2.5 \mu \mathrm{M}$ under normal circumstances and rise to $10 \mu \mathrm{M}$ in people who ingest selenium supplements. ${ }^{22,23)}$

As a marker of degranulation of mast cells, $\beta$-hexosaminidase release is commonly well used. ${ }^{4)}$ In this study, the release of $\beta$-hexosaminidase significantly increased upon antigen-stimulation in IgE-sensitized cells. Antigeninduced $\beta$-hexosaminidase release was significantly suppressed by SeMet treatment in a dose-dependent manner, and it was most inhibited at a concentration of $10 \mu \mathrm{M}$ of SeMet. Antigen-induced $\beta$-hexosaminidase release was not suppressed by $10 \mu \mathrm{M}$ of Met (same concentration as SeMet). According to the manufacturer's information, the medium (MEM, \#M0268, Sigma-Aldrich) used in this experiment originally contains $100.5 \mu \mathrm{M}$ Met; the addition of $10 \mu \mathrm{M}$ of Met is considered to be small and not to affect the degranulation. In addition, there is no report that $10 \mu \mathrm{M}$ of Met suppresses degranulation or allergic responses. Therefore, we considered that SeMet suppressed degranulation at $10 \mu \mathrm{M}$, not Met.

It is well-known that mast cell degranulation is closely related to calcium movement. ${ }^{7)}$ A transient increase of the intracellular calcium concentration occurs upon mast cell activation. The blockage of calcium levels changes attenuates degranulation. In this study, calcium mobilization was significantly increased upon antigen-stimulation in IgE-sensitized cells and was significantly inhibited by SeMet treatment. These results hint that SeMet-mediated suppression of calcium mobilization impaired degranulation.

Cytokines such as IL-4 and TNF- $\alpha$ are deeply involved in allergic reactions. IL-4 is essential for the production of IgE, and also involved in allergic-type T-helper (Th) 2 cells development. ${ }^{24)} \mathrm{TNF}-\alpha$ is a potent proinflammatory mediator that is generated and secreted upon antigen stimulation in IgEsensitized mast cells. ${ }^{25,26)}$ We evaluated the effect of SeMet on mRNA expression and protein secretion of IL- 4 and TNF- $\alpha$ upon antigen stimulation in IgE-sensitized cells. SeMet suppressed the antigen-induced upregulation of IL- 4 and TNF- $\alpha$ mRNA in IgE-sensitized cells and decreased the protein secretion of IL- 4 and TNF- $\alpha$ as well. These results imply that SeMet exerts anti-allergic effects by controlling cytokine levels in RBL-2H3 cells.

Syk is a crucial molecule in mast cell activation associated with Fe\&RI signaling and is considered one of the promising therapeutic targets for allergic diseases. ${ }^{27)}$ Syk activation is an important prerequisite for Fc\&RI-mediated mast cell activation. ${ }^{28)}$ The activation of Syk increases the mobilization of calcium, ${ }^{29)}$ and also activates downstream signaling molecules such as Akt and MAPKs. ${ }^{30)}$ Phosphorylation of Akt and MAPKs in mast cells has been reported to be associated with the expression of cytokines such as IL-4 and TNF- $\alpha .{ }^{4)}$ Although the activation of MAPKs by stimulation such as Staphylococcus aureus has been reported to be suppressed by selenium, ${ }^{31)}$ the effect of selenium on the activation of MAPKs by antigen stimulation in IgE-sensitized mast cells is not well known. In this study, antigen-induced activation of Syk was significantly attenuated by SeMet treatment. Moreover, antigen-induced activation of Akt and MAPKs, which are downstream molecules of Syk, was also suppressed by SeMet treatment. From these results, it is suggested that Syk may be one of the target molecules of SeMet. It has been reported that an increase in oxidative stress contributes to the activation of mast cells. ${ }^{15)}$ Furthermore, some reports showed that an increase in oxidative stress is also involved in the activation of Syk, Akt, and MAPKs. ${ }^{32,33)}$ Since it is well known that selenium plays a vital role in defense of oxidative stress, ${ }^{9,34,35)}$ SeMet may inhibit the activation of Syk via a cellular antioxidant system and inhibit allergic reactions by $\operatorname{IgE}$ antigen complexes.

In conclusion, our present study demonstrates that SeMet suppresses antigen-induced degranulation, and mRNA expression and protein secretion of IL- 4 and TNF- $\alpha$, and inhibits antigen-induced mobilization of calcium and activation of Syk, Akt, ERK1/2, p38, and JNK in IgE-sensitized RBL-2H3 cells. Our results provide valuable information that may be useful in the prevention and treatment of allergic diseases. Further studies are needed to elucidate the mechanism of the control of allergic reactions by SeMet.

Acknowledgments This research was supported in part by a Grant-in-Aid for Young Scientists (B) (JP15K18912) from the Japan Society for the Promotion of Science. The authors thank Ms. Mayuko Okada, Mr. Atsushi Inaoka, Mr. Shunsuke Namura, and Dr. Hideki Kakutani of Setsunan University for excellent technical assistance.

Conflict of Interest The authors declare no conflict of interest.

\section{REFERENCES}

1) Amin K. The role of mast cells in allergic inflammation. Respir. Med., 106, 9-14 (2012).

2) Beaven MA, Metzger H. Signal transduction by Fc receptors: the Fc epsilon RI case. Immunol. Today, 14, 222-226 (1993).

3) Rivera J, Gilfillan AM. Molecular regulation of mast cell activation. J. Allergy Clin. Immunol., 117, 1214-1225 (2006).

4) Gilfillan AM, Tkaczyk C. Integrated signalling pathways for mastcell activation. Nat. Rev. Immunol., 6, 218-230 (2006).

5) Bradding P, Roberts JA, Britten KM, Montefort S, Djukanovic R, Mueller R, Heusser CH, Howarth PH, Holgate ST. Interleukin-4, -5 , and -6 and tumor necrosis factor-alpha in normal and asthmatic airways: evidence for the human mast cell as a source of these cytokines. Am. J. Respir. Cell Mol. Biol., 10, 471-480 (1994).

6) Siraganian RP, Zhang J, Suzuki K, Sada K. Protein tyrosine kinase Syk in mast cell signaling. Mol. Immunol., 38, 1229-1233 (2002).

7) Beaven MA, Rogers J, Moore JP, Hesketh TR, Smith GA, Metcalfe JC. The mechanism of the calcium signal and correlation with histamine release in 2H3 cells. J. Biol. Chem., 259, 7129-7136 (1984).

8) Fairweather-Tait SJ, Collings R, Hurst R. Selenium bioavailability: current knowledge and future research requirements. Am. J. Clin. Nutr., 91, 1484S-1491S (2010).

9) Kryukov GV, Castellano S, Novoselov SV, Lobanov AV, Zehtab O, Guigo R, Gladyshev VN. Characterization of mammalian selenoproteomes. Science, 300, 1439-1443 (2003).

10) Knowles SO, Grace ND. Selenomethionine as a safer substitute for barium selenate in long-acting injectable Se supplements for foodproducing animals. J. Agric. Food Chem., 65, 8120-8127 (2017).

11) Ariaee N, Farid R, Shabestari F, Shabestari M, Jabbari Azad F. Trace elements status in sera of patients with allergic asthma. Reports Biochem. Mol. Biol., 5, 20-25 (2016).

12) Misso NL, Powers KA, Gillon RL, Stewart GA, Thompson PJ. Re- 
duced platelet glutathione peroxidase activity and serum selenium concentration in atopic asthmatic patients. Clin. Exp. Allergy, 26, 838-847 (1996).

13) Yamada $T$, Saunders $T$, Kuroda $S$, Sera $K$, Nakamura $T$, Takatsuji T, Nose Y, Hara T, Fukuoka College of Obstetricians and Gynecologists, Pediatric Association of Fukuoka District. Cohort study for prevention of atopic dermatitis using hair mineral contents. J. Trace Elem. Med. Biol., 27, 126-131 (2013).

14) Tsukahara H, Shibata R, Ohshima Y, Todoroki Y, Sato S, Ohta N, Hiraoka M, Yoshida A, Nishima S, Mayumi M. Oxidative stress and altered antioxidant defenses in children with acute exacerbation of atopic dermatitis. Life Sci., 72, 2509-2516 (2003).

15) Chelombitko MA, Fedorov AV, Ilyinskaya OP, Zinovkin RA, Chernyak BV. Role of reactive oxygen species in mast cell degranulation. Biochemistry, 81, 1564-1577 (2016).

16) Arakawa $T$, Deguchi $T$, Sakazaki F, Ogino $H$, Okuno $T$, Ueno $H$. Supplementary seleno-L-methionine suppresses active cutaneous anaphylaxis reaction. Biol. Pharm. Bull., 36, 1969-1974 (2013).

17) Arakawa $T$, Sugiyama $T$, Matsuura $H$, Okuno $T$, Ogino $H$, Sakazaki F, Ueno $\mathrm{H}$. Effects of supplementary seleno-L-methionine on atopic dermatitis-like skin lesions in mice. Biol. Pharm. Bull., 41, 1456-1462 (2018).

18) Seldin DC, Adelman S, Austen KF, Stevens RL, Hein A, Caulfield JP, Woodbury RG. Homology of the rat basophilic leukemia cell and the rat mucosal mast cell. Proc. Natl. Acad. Sci. U.S.A., 82, 3871-3875 (1985).

19) Passante E, Frankish N. The RBL-2H3 cell line: its provenance and suitability as a model for the mast cell. Inflamm. Res., 58, 737-745 (2009).

20) Murata K, Takano S, Masuda M, Iinuma M, Matsuda H. Antidegranulating activity in rat basophil leukemia RBL-2H3 cells of flavanone glycosides and their aglycones in citrus fruits. $J$. Nat. Med., 67, 643-646 (2013).

21) Arakawa $T$, Yamamura $T$, Hattori $T$, Hayashi H, Mori A, Yoshida A, Uchida C, Kitagawa M, Onozaki K. Contribution of extracellular signal-regulated kinases to the IL-1-induced growth inhibition of human melanoma cells A375. Int. Immunopharmacol., 8, 80-89 (2008).

22) $\overline{\text { Combs }}$ GFJ Jr, Midthune DN, Patterson KY, Canfield WK, Hill AD, Levander OA, Taylor PR, Moler JE, Patterson BH. Effects of selenomethionine supplementation on selenium status and thyroid hormone concentrations in healthy adults. Am. J. Clin. Nutr., 89, 1808-1814 (2009).

23) Kandaş NO, Randolph C, Bosland MC. Differential effects of sele- nium on benign and malignant prostate epithelial cells: stimulation of LNCaP cell growth by noncytotoxic, low selenite concentrations. Nutr. Cancer, 61, 251-264 (2009).

24) Brown MA, Hural J. Functions of IL-4 and control of its expression. Crit. Rev. Immunol., 17, 1-32 (1997).

25) Turner MD, Nedjai B, Hurst T, Pennington DJ. Cytokines and chemokines: at the crossroads of cell signalling and inflammatory disease. Biochim. Biophys. Acta, 1843, 2563-2582 (2014).

26) Gordon JR, Galli SJ. Mast cells as a source of both preformed and immunologically inducible TNF-alpha/cachectin. Nature, 346, 274-276 (1990).

27) Meltzer EO, Berkowitz RB, Grossbard EB. An intranasal Sykkinase inhibitor (R112) improves the symptoms of seasonal allergic rhinitis in a park environment. J. Allergy Clin. Immunol., 115, 791-796 (2005)

28) Kambayashi T, Koretzky GA. Proximal signaling events in $\mathrm{Fc} \varepsilon$ RI-mediated mast cell activation. J. Allergy Clin. Immunol., 119, 544-552 (2007).

29) Roa M, Paumet F, Le Mao J, David B, Blank U. Involvement of the ras-like GTPase rab3d in RBL-2H3 mast cell exocytosis following stimulation via high affinity IgE receptors (Fc epsilonRI). J. Immunol., 159, 2815-2823 (1997).

30) Siraganian RP, de Castro RO, Barbu EA, Zhang J. Mast cell signaling: the role of protein tyrosine kinase Syk, its activation and screening methods for new pathway participants. FEBS Lett., 584, 4933-4940 (2010).

31) Wang H, Bi C, Wang Y, Sun J, Meng X, Li J. Selenium ameliorates Staphylococcus aureus-induced inflammation in bovine mammary epithelial cells by inhibiting activation of TLR2, NF-kappaB and MAPK signaling pathways. BMC Vet. Res., 14, 197 (2018).

32) Takano T, Sada K, Yamamura H. Role of protein-tyrosine kinase syk in oxidative stress signaling in B cells. Antioxid. Redox Signal., 4, 533-541 (2002).

33) Qi S, Feng Z, Li Q, Qi Z, Zhang Y. Inhibition of ROS-mediated activation Src-MAPK/AKT signaling by orientin alleviates $\mathrm{H}_{2} \mathrm{O}_{2-}$ induced apoptosis in PC12 cells. Drug Des. Devel. Ther., 12, 3973-3984 (2018).

34) Liu H, Bian W, Liu S, Huang K. Selenium protects bone marrow stromal cells against hydrogen peroxide-induced inhibition of osteoblastic differentiation by suppressing oxidative stress and ERK signaling pathway. Biol. Trace Elem. Res., 150, 441-450 (2012).

35) Wu RTY, Cao L, Chen BPC, Cheng W-H. Selenoprotein H suppresses cellular senescence through genome maintenance and redox regulation. J. Biol. Chem., 289, 34378-34388 (2014). 